\title{
Erratum: Boland, P.M., et al. Immunotherapy for Colorectal Cancer, Cancers 2017, 9, 50
}

\author{
Patrick M. Boland ${ }^{1}$ (D) and Wen Wee Ma ${ }^{2, *}$
}

1 Roswell Park Cancer Institute, Department of Medicine, Elm and Carlton St, Buffalo, NY 14263, USA; Patrick.Boland@RoswellPark.org

2 Mayo Clinic, Division of Medical Oncology, 200 First St. SW, Rochester, MN 55905, USA

* Correspondence: ma.wen@mayo.edu; Tel.: +1-507-293-0462

Received: 20 April 2020; Accepted: 21 April 2020; Published: 22 May 2020

The authors wish to make the following corrections to this paper [1]:

The funding information was missing in the original version. The following acknowledgement of funding support should be included:

Funding: This work was partially supported by American Cancer Society Internal Research Grant \#126771-IRG-14-194-11-IRG.

These changes do not affect the scientific results. The manuscript will be updated and the original version will remain online on the article webpage, with a reference to this erratum. The authors would like to apologize for any inconvenience caused to the readers by this change.

\section{Reference}

1. Boland, P.M.; Ma, W.W. Immunotherapy for Colorectal Cancer. Cancers 2017, 9, 50.

(C) 2020 by the authors. Licensee MDPI, Basel, Switzerland. This article is an open access article distributed under the terms and conditions of the Creative Commons Attribution (CC BY) license (http://creativecommons.org/licenses/by/4.0/). 